\title{
CORRESPONDENCE
}

\author{
Clinical responsibility \\ I J T Davies, FRCPED. \\ Monetary value of a \\ human life \\ J C Stewart, MRCS; J S Robertson, FFCM . . . . 105 \\ Adjuvant liver perfusion in colorectal \\ cancer \\ L P Fielding, FRCS; I Taylor, FRCS. . . . . . . 105 \\ Maternal pethidine and neonatal \\ depression \\ P W Barritt, MB, and others......... 106 \\ Beta-blocking drugs in diabetes

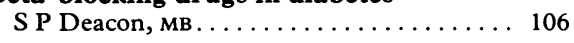 \\ Beta-blockers and thyroid function \\ W Michie, FRCSED . . . . . . . . . . . . . . . . 106 \\ "Basic Health Education" \\ $M$ Spira, MB, and V L Irwin, BM; J A M \\ Gray, $\mathrm{MB}, \mathrm{DPH} \ldots \ldots \ldots \ldots \ldots \ldots \ldots$ \\ Teratogenic effects of waste anaesthetic \\ gases \\ P J Tomlin, fFarcs . . . . . . . . . . 108 \\ Inheritance of Marfan's syndrome

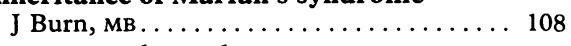 \\ Paracetamol overdosage \\ W R Jondorf, PHD; $M$ J Tarr, BPHARM, and \\ V Fenton-May, BPHARM........... 109 \\ Confidentiality and life insurance \\ V H Kendall, AcII . . . . . . . . . . . . . . . 109
}

Dietary cholesterol and atherosclerosis

R W D Turner, FRCP . . . . . . . . . . . . . 109

Antidepressants-yes or no?

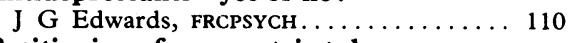

Positioning of nasogastric tubes

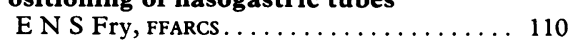

Smoking and asthma

F E de W Cayley, FRCP.

Return to normal of Argyll Robertson

pupils after treatment

R Cooling, FRCS.

Failure of heparin to alter the outcome of pneumococcal meningitis

J Stuart, FRCPED, and J M Anderson, MRCP 111

Reticulocytopenia in immune haemolytic anaemia

O B Eden, MrCP, and Elizabeth M Innes,

FRCPED $\ldots \ldots \ldots \ldots \ldots \ldots \ldots \ldots \ldots 11$

Bronchiectasis in acute leukaemia

J W M van der Meer, MD, and others ..... 111

Hair in the theatre

N A Simmons, FRCPATH.

Richter's hernia at site of insertion of

laparoscope

T P N Jenkins, frCs . . . . . . . . . . 112

Uncovering physical illness in elderly

patients with dementia

Marjorie K Hare, MRCPSYCH......... 112

Ink caps and mushrooms

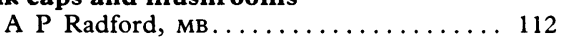

The Steve Biko inquest

R Hoffenberg, FRCP . . . . . . . . . . . 112

Distinction awards

J F Gould, FRCSED . . . . . . . . . . . 112

Shadow over Maltese medicine

Kwok Ning Chan; F Carabott . . . . . . . . . 112

Dental anaesthetic fees

E O Evans, FrCGP . . . . . . . . . . . . 113

Ban on dental anaesthetics

C S Ward, FFARCS.

Bringing deputising services into the

fold

G M Jones, MRCGP ; J D Nicholas, MB . . . . . 113

Clothier Report and the dispensing

doctor

A R Rogers, MB.

New consultant contract

A H B Masson, FFARCs; J L T Birley, FRCP;

D Adler, MRCs; N F Coghill, FRCP; P Ward, FRCR; P K Ganguli, MB, DMRT . . . . . . . . 114

Rheumatology and Rehabilitation

Group Committee

A P H Randle, FRCPI . . . . . . . . . 115

Points from letters Hospital noise (H A

Fleming); Golfers' wrist (K T Ulahannan); Getting the baby to breathe deeply (G W Vella); Cost of family planning (E M Sklar); Skateboard injuries (J R Oakley); Psychological evaluation in cases of self poisoning ( $P$ J Todd

$\mathrm{J} W \mathrm{~W}$ odd $) \ldots \ldots \ldots \ldots \ldots \ldots \ldots \ldots \ldots 115$
Correspondents are urged to write briefly so that readers may be offered as wide a selection of letters as possible. So many are being received that the omission of some is inevitable. Letters must be signed personally by all their authors.

\section{Clinical responsibility}

SIR,-I have read with the greatest interest your two articles on clinical responsibility (17 December, p 1584, and 24-31 December, p 1637) and you are to be congratulated on sponsoring the conference which gave rise to them and on the way in which the discussions were recorded. There is, however, one important point which is central to the whole theme of clinical responsibility which was not discussed. The arguments presented tended to consider the changing role of hospital doctors in relation to other groups of workers within NHS hospitals. This is really too simplistic and underlines one of the fundamental defects in the present organisation of the hospital service. It is surely axiomatic that in a large and complex institution like a hospital all groups which work there are useful for the running of the institution, but the importance of the different groups will vary according to the use which is being made of the institution. In other words it is necessary to analyse critically what is being done for individual patients in hospital. For example, if a patient has acute intestinal obstruction then no one is as important as the surgeon who will operate-in the last analysis he could perform his function alone, doing all the essential work himself, and still stand a chance of curing or relieving the patient. No other group of workers in this example is in this situation; surely this must give him pride of place in any hierarchy or team. At the other extreme is the need to admit to hospital (the same institution as the surgeon uses) a feeble old man living alone who has got cold, hungry, and a bit confused; his needs for a doctor are minimalhe needs only loving care. Confusion arises because the same institution, the hospital, is used for a vast spectrum of disease, social deprivation, and custodial purposes without it being clearly appreciated that the one institution performs social as well as medical functions. By tradition doctors have been involved in the running of hospitals and therefore involved in all the functions for which hospitals are used.

It would clarify our thinking if it was appreciated that the National Health Service is a misnomer. The NHS is really an amalgam of three services which are only loosely interrelated: the national illness service (genera practitioners and hospital consultants with their useful and necessary supporting services), the national social services concerned with the social aspects of people who happen also to have an acute or chronic illness, and a national wellness service (health education, screening well-baby clinics, health visitors, etc).

If doctors could get on with the curing or alleviating of sick patients they would be satisfied, but they become increasingly frustra- ted when the social aspects of their patients impinge on their ability to get on with their proper job. As individuals who are mostly humane and caring, doctors are naturally concerned about the social aspects of their patients, but they do not feel that "hospital" facilities should have to compete for resources with "hospice" facilities to the detriment of other patients who still require "hospital" facilities. In respect of organising and deploying "hospice" facilities most clinicians would be content to be part of a team and not carry ultimate clinical responsibility. In respect of organising "hospital" facilities doctors would reasonably expect to be the leaders and carry full clinical responsibility.

Your discussants mention the "problems" of trade unionism and the aspirations of other professional groups within the NHS to organise themselves the better to influence events, protect their interests, and hopefully promote excellence. These events should be seen in perspective-the majority of hospital consultants do not feel particularly threatened by them, although admittedly some see the recent developments as the "thin edge of the wedge." One must remember that trade unionism in hospitals is a very recent happening, that the "professions necessary to medicine" have been appallingly poorly paid until the last few years, that we live in times in which the power to disrupt is widely regarded as a legitimate negotiating weapon, and that despite all this the vast majority of those in "professions necessary to medicine" (including laboratory technicians and radiographers) are as concerned as doctors about declining resources and are as dedicated as doctors to the 
welfare of individual patients. It is still early days in these developments and inevitably there must be stresses and straining until the right balance is found.

The serious and frightening moral dilemma confronting doctors which they have so far failed to face is - at what point does it become professionally irresponsible to carry on maintaining clinical responsibility when supporting resources generally are steadily and surreptitiously declining?

I J T Davies

Raigmore Hospital,

Inverness

\section{Monetary value of a human life}

SIR,-Dr W I Card and Mr G H Mooney in their interesting paper (24-31 December, p 1627) show the difficulty of making decisions in the NHS and illustrate how rational solutions may be reached by use of a decision theory model. This type of analysis is probably familiar to the policy makers at the Department of Health and Social Security, but many, who work in hospitals, may find the theory strange and difficult to handle. With the help of games theory, however, it should be possible to construct a simple model displaying the economic forces which must eventually shape policy. What follows is a broad outline of the "Hospital Management Game." Obviously advanced players would require a far more complex model but it would have the same economic core.

The fundamental rule is that the hospital manager must keep solvent to stay in the game; if he is to win he must show sufficient profit to enable him to take over other hospitals. He makes a profit when he provides a utility with a monetary value in excess of its cost-namely, pu $>$ C. For the sake of simplicity only two outcomes are considered, survival and death. The manager must try to increase the probability of survival and this can only be achieved by the systematic monitoring of all admissions. To rely on the excellence of the clinical team would be most unwise, as the highly proficient are prone to undertake the treatment of high risk cases. Clinical performance must be audited, and control placed firmly in the hands of those who show a consistent profit.

The measurement of $u$, the utility of survival, is, as Dr Card and $\mathrm{Mr}$ Mooney have pointed out, difficult and contentious, but it is surely reasonable to relate it to the productive capacity. Unfortunately it is often impossible to estimate the productive capacity of a patient-one acute coronary thrombosis may look very like another-but this problem could be solved by the use of a centralised computer linking the DHSS and the Inland Revenue. The record could be adjusted annually and an accurate figure for each patient relayed to the intensive care unit within a very short time. The importance of this service can scarcely be overestimated, as without it physicians and surgeons could easily commit the catastrophic economic error of treating the wrong patient. Now comes the disagreeable element in the systemcost. Even the finest centre of excellence must in the end prove to be but a splendid façare if its costs exceed its profits. At all times stringent economy should be the rule. Unproductive beds must be weeded out and redundant staff dismissed. However, it is important that a misguided emphasis on humane values should not lead to disproportionate economies in the maintenance of the hospital fabric. Well-maintained institutions have a high utility value. Furthermore, neglect of the fabric may lead insidiously to absurd capital costs far in excess of any value which might be assigned to the patient-orientated functions of the hospital.

The model makes it clear that geriatric inpatient treatment is a hopelessly bad buy: an appeal to general implicit values may provide some additional money but never enough to cover the cost. The winning strategy must lie in emphasising community care and gradually reducing beds and staff. This should be done with circumspection and with proper regard for public relations. Poor presentation of hospital policy can cause much misunderstanding and may even give rise to irrational assertions of individual values, thus causing much local difficulty and costly delays. Even in the most rationally planned organisations abuses tend to creep in and managers must be vigilant and ensure that black markets do not develop within their hospitals. Old people are often selfish and, if not watched, may succumb to the temptation to buy treatment over and above what is allocated to them by the regulations. Also the young sometimes attach sentimental value to their aged parents and may attempt to purchase life-saving remedies, despite the fact that these are inappropriate, uneconomic, and contrary to public policy. Possibly these evils could be averted by a contributory scheme for the purchase of negative years, payments being made during the worker's productive life. As well as reducing the beneficiary's official age, the negative years would serve as a useful low-cost incentive for the nation's working force.

Some may feel that this model is too idealistic, but, provided they grasp the essential fact that a man's life is worth a finite amount of money, they will undoubtedly find their own way to a rational solution of the problems of the NHS. We should all take encouragement from the scientific advances which have now made it possible to develop an extremely valuable military weapon-the neutron bomb-which does no damage to property, thus at last making an economically successful war a real possibility. Surely, this should spur us all on to make an equal success of our Health Service.

Stone House Hospital,

Dartford,
Kent

SIR,-The proposals of Dr W I Card and Mr G H Mooney (24-31 December, p 1627) to seek a consistent financial valuation for human life for the purpose of resource allocation for forms of health care are inappropriate. The use of such valuations in decision-making would lead to unsound and inhumane decisions.

Their argument is based on the fallacy that the objective of medical treatment is to "save life" (that is, "prevent death"). We are not, nor do we seek to be, immortal. We may postpone but cannot ultimately prevent death; we should not pretend to ourselves or to others that we can. In making decisions most clinicians intuitively take account of the likely duration and quality of life in the extra years that are likely to result in a way no "formula" will achieve.

The proper objectives of medicine are humanitarian. We must seek to prolong life only where expectations as to quality warrant this. It is not costly to "cure" pneumonia with antibiotics. But to do so in an octogenarian who has prostatic secondaries in his spine would be inhumane. In such circumstances life might be deemed to have a "negative value" both to the individual and to society. In other circumstances there may be wide divergence between the values of life of an individual to himself and to society-the psychopath who enjoys his life but is an expensive hazard to others, and the genius with painful and chronic disease and craving for euthanasia but who is an asset to the community, are both extreme examples. Not only have we separate scales for value to "self" and to "society," but both of these range from highly "positive" values to low "negative" ones. The use of any form of "mean" in these circumstances is a nonsense.

The absurdity of using a measure unrelated to the real objective is most beautifully illustrated by the last of the illustrative examples tabulated by Drs Card and Mooney. The purpose of building blocks of flats is not to "save life" but to provide homes in which families may live in reasonable comfort and security. Building regulation changes to ensure that flats do not collapse would still have been necessary to give sufficient peace of mind and confidence to enable high-rise flats to be let even if nobody had died at Ronan Point-and if there had been no death in that disaster the "implied value of life" would doubtless have been infinity, not a mere $£ 20 \mathrm{~m}$. In fact, of course, a value is "implied" only when the expenditure was incurred with the express intention of securing the object to be valued. If expenditure is incurred for a different reason it is irrelevant to the valuation of any object secured as a byproduct.

One of the great dangers of our time is the development of pseudoscientific management theories which take account of only those factors which can be measured and expressed in numbers and ignore other and equally important aspects of the situation. We must not allow such theories to be applied in situations where they can do as much damage to the Health Service as they have in industry. There, because accountants were able to compute so-called economies of scale but did not know how to measure the diseconomies caused by the consequent deterioration of labour relations, governments pursued policies of promoting "mergers," large company growth, and nationalisation. These have had a detrimental effect on our economy. While it is possible in several ways to assess in financial terms the value for some particular purpose of a human life, we have no means of valuing suffering or pain. Statistics are valuable only if used wisely. We need to learn when not to use them and how to use them better.

J S ROBERTSON

Scunthorpe Health District,
Scunthorpe, Humberside

Adjuvant liver perfusion in colorectal cancer

SIR,-It is encouraging to see in the paper by $\mathrm{Mr}$ I Taylor and others (19 November, p 1320) new ideas being tested for the treatment of patients with colorectal cancer when one remembers that only one in four patients are alive five years after hospital treatment. However, the design and conduct of randomised trials in large-bowel cancer is a difficult subject. Even when relatively small numbers of patients are being compared, whether formally or informally, it is helpful to report as much as possible about the matching of the groups. It would have been interesting to know more detail about the staging of the tumoursfor example, the harvest of lymyh nodes and the number of nodes involved, especially in the patients who developed liver secondaries.

The authors seem to have assumed that heparin has no intrinsic action to prevent the development of secondary tumours. However, there is evidence ${ }^{1}$ to suggest that anticoagulants 